\title{
Active management of third stage of labour: a comparative study of intra-umbilical oxytocin versus intramuscular oxytocin
}

\author{
Neerja Gupta*, Manjushree Athokpam
}

Department of Obstetrics and Gynecology, Muzaffar Nagar Medical College, Muzaffarnagar, Uttar Pradesh, India

Received: 21 May 2017

Accepted: 20 June 2017

\section{*Correspondence:}

Dr. Neerja Gupta,

E-mail: dr.neerja55@gmail.com

Copyright: () the author(s), publisher and licensee Medip Academy. This is an open-access article distributed under the terms of the Creative Commons Attribution Non-Commercial License, which permits unrestricted non-commercial use, distribution, and reproduction in any medium, provided the original work is properly cited.

\begin{abstract}
Background: Postpartum haemorrhage is a single major and leading cause of maternal morbidity and mortality, not only in the developing countries but also in developed countries. Every 4 minutes one woman dies from pregnancy or child birth related complications. The present study is to compare oxytocin used via intra-umbilical or intramuscular route in the active management of third stage of labour with respect to duration and amount of bleeding.

Methods: Four hundred pregnant women at term of a singleton pregnancy with spontaneous onset of labour were included in the study and were randomly divided into 2 groups of 200 women each. Group 1, intra-umbilical oxytocin $10 \mathrm{U}$ diluted in $10 \mathrm{ml}$ of saline, and Group 2, intramuscular oxytocin $10 \mathrm{U}$ were given after the delivery of baby.

Results: The outcome criteria with respect to third stage of labour were: duration of the $3^{\text {rd }}$ stage of labour, blood loss by volume, difference in haemoglobin. A significant reduction in duration of third stage $(\mathrm{p}=0.001)$ and blood loss in third stage ( $\mathrm{p}=0.0001$ ) in intra-umbilical oxytocin group was found when compared with intramuscular oxytocin use. Conclusions: Intra-umbilical oxytocin is better alternative to intramuscular oxytocin in active management of third stage of labour.
\end{abstract}

Keywords: Active management of $3^{\text {rd }}$ stage of labour, Caesarian section, Post partum haemorrhage

\section{INTRODUCTION}

India has Maternal Mortality Ratio of 167/1,00,000 live births, Maternal Mortality Rate 11.7, U.P. has Maternal Mortality Ratio 285 and Maternal Mortality Rate of 22.1 as per census 2011-2013. The most common cause of maternal mortality is haemorrhage which accounts for $25-30 \%$ of maternal mortality of which postpartum haemorrhage is a significant cause and one of the most dreaded and common complication of third stage of labour accounting for $15-25 \%$ of maternal deaths in India $^{1,2}$ The duration of third stage of labour is from the birth of the baby to the delivery of the placenta. The complications of third stage of labour threatens the mother's life. The most common complication is postpartum hemorrhage, which remains a leading cause of maternal mortality, especially in the developing countries. ${ }^{3}$ The incidence of the PPH is $3.9 \%$ of vaginal deliveries and $6.4 \%$ of $\mathrm{CS}^{4}$

Postpartum bleeding or postpartum haemorrhage (PPH) is defined as more than $500 \mathrm{ml}$ of blood following childbirth, or $10 \%$ drops in haematocrit from the admission to post-delivery or till the end of puerperium. Active pharmacologic management of the third stage of labour is common today and has resulted in a significant decrease in early and late postpartum haemorrhage and in total maternal peri-partum mortality and morbidity. ${ }^{5}$ AMTSL involves the use of prophylactic oxytocic drug within 1-2 minute of birth, expulsion of placenta by controlled cord traction followed by uterine massage. Oxytocin requires parental route. So, the routine practice 
in AMSTL is oxytocin 10U I/M given within 2 mins of delivery of baby. The onset of action of I/M oxytocin is $3-5$ mins and persist for $2-3 \mathrm{hrs}$. One of these methods is the administration of oxytocin via the umbilical vein for the delivery of placenta. Umbilical vein oxytocin injection directs treatment to the placental bed and uterine wall, resulting in earlier uterine contraction and placental separation.

This study aims to evaluate whether intra-umbilical oxytocin in the AMTSL can reduce the duration and amount of bleeding as compared to routine protocol, given in same doses.

\section{METHODS}

This was a randomized prospective comparative study conducted in Muzaffarnagar Medical College, Muzaffarnagar, UP from April 2015 to September 2016.

\section{Inclusion criteria}

- Cephalic presentation,

- Singleton pregnancies,

- Gestational age more than 37 weeks,

- Previous normal vaginal delivery,

- Age 18-35 years,

- $\mathrm{Hb} \geq 11 \mathrm{~g} / \mathrm{dl}$.

\section{Exclusion criteria}

- Preterm labour,

- Previous caesarean section,

- Rh-negative mothers,

- Intrauterine fetal death,

- Malpresentation,

- Multiple pregnancy,

- Polyhydramnios,

- Oxytocin induction or augmented cases,

- PROM,

- IUGR,

- Medical disorders and hypertensive disorders of pregnancy,

- Grand multipara,

- History of PPH in previous pregnancy,

- Anaemia $(\mathrm{Hb}<11 \mathrm{~g} / \mathrm{dl})$.

Cluster sampling technique was used to group them into two. In group 1, 200 women received 10U intra-umbilical oxytocin, diluted in $10 \mathrm{ml}$ normal saline and 200 women in Group 2, received $10 \mathrm{U}$ intramuscular Oxytocin after delivery of baby.

Labour was monitored with partogram in the labour room. In group 1, after delivery of the baby and cord clamping, umbilical vein was identified and 10-unit's oxytocin diluted in $10 \mathrm{ml}$ normal saline was injected. Placental delivery was conducted by control cord traction. Injection-delivery time and the third stage duration were recorded using a clock. In group 2, oxytocin 10 units IM was given to the mother, recording events in the same way as in group 1.

Blood loss was collected in a bowl by firmly pressing the bowl against the perineum after the delivery of the baby and was measured by measuring cup in millilitres. Soaked gauges, pads and blood clots were weighed standardizing one-millilitre of blood to weighs 1- gram. Women were followed for one-hour post-delivery and all additional blood loss was recorded. Baby's Apgar, weight, sex and weight of placenta were noted. The mean duration of third stage of labour and the mean blood loss was analysed in relation to age, parity, duration of pregnancy, duration of labour, baby's weight. All women had repeat haemoglobin after 24 hours of delivery.

\section{Data analysis}

The mean duration of third stage of labour and the mean blood loss during third stage were analysed in relation to parity, duration of pregnancy, duration of labour. The level of significance tested by t test and chi square test. The resultant $\mathrm{P}$ value is considered significant if $\mathrm{p}<0.05$. SPSS version 10 has been used for calculations and tabulations.

\section{RESULTS}

The two groups of women were similar in age, parity, gestational age and duration of first and second stage of labour (Table 1).

Table 1: Baseline profile (mean \pm SD).

\begin{tabular}{|c|c|c|c|}
\hline Characteristics & Group 1 & Group 2 & p value \\
\hline Age & $26.38 \pm 5.058$ & $25.89 \pm 4.907$ & $\begin{array}{l}\mathrm{p}=0.433 \\
(\mathrm{NS})\end{array}$ \\
\hline Parity & $1.725 \pm 1.036$ & $2.45 \pm 1.133$ & $\begin{array}{l}\mathrm{p}=0.878 \\
(\mathrm{NS})\end{array}$ \\
\hline Gestational age & $38.25 \pm 0.87$ & $38.49 \pm 0.86$ & $\mathrm{p}=0.602$ \\
\hline $\begin{array}{l}1^{\text {st }} \text { stage } \\
\text { duration }\end{array}$ & $7.52 \pm 1.09$ & $7.54 \pm 1.062$ & $\mathrm{p}=0.181$ \\
\hline $\begin{array}{l}2^{\mathrm{n}} \text { stage } \\
\text { duration }\end{array}$ & $18.56 \pm 8.165$ & $18.636 \pm 8.39$ & $\mathrm{p}=0.993$ \\
\hline
\end{tabular}

There was statistically significance difference in the duration of third stage of labour using either IU, IM oxytocin (1.703 versus 2.93 mins). The third stage blood loss was more in IM than Intra-umbilical group, however it is significantly higher when blood loss for one hour postpartum was taken ( 95.35 vs $125.9 \mathrm{ml} \mathrm{p}=0.00001)$ in IU and IM respectively (Table 2). There was no need for additional oxytocin to control bleeding in the postpartum period. The fall in $\mathrm{Hb}$ after $24 \mathrm{hrs}$ of delivery was $(0.11 \pm 0.13$ vs $0.12 \pm 0.13)$ in group 1,2 . There was no statistically significant fall in $\mathrm{Hb}$ after $24 \mathrm{hrs}$ of delivery. There was no PPH and no retained placenta in either groups. 
Table 2: Showing duration of third stage of labor in group 1, group 2.

\begin{tabular}{|c|c|c|}
\hline Time (mins) & Group $1(\%)$ & Group $2(\%)$ \\
\hline$<1$ & $8(4 \%)$ & $10(5 \%)$ \\
\hline 1 to 2 & $140(70 \%)$ & $12(6 \%)$ \\
\hline 2 to 3 & $25(12.5 \%)$ & $35(17.5 \%)$ \\
\hline 3 to 4 & $17(10 \%)$ & $135(67.5 \%)$ \\
\hline$>4$ & $10(5 \%)$ & $8(4 \%)$ \\
\hline Mean \pm S.D (mins) & $1.703 \pm 0.918$ & $2.931 \pm 0.87405$ \\
\hline
\end{tabular}

Table 3: Showing blood loss in third stage of labor in group 1, group 2.

\begin{tabular}{|c|c|c|}
\hline Ml & Group $1(\%)$ & Group $2(\%)$ \\
\hline$<50$ & $7(3.5 \%)$ & $6(3 \%)$ \\
\hline 50 to 100 & $130(65 \%)$ & $37(18.5 \%)$ \\
\hline 100 to 150 & $42(21 \%)$ & $135(67.5 \%)$ \\
\hline 150 to 200 & $11(5.5 \%)$ & $12(6 \%)$ \\
\hline$>250$ & $7(5 \%)$ & $10(5 \%)$ \\
\hline Mean =/- S.D.(ML) & $95.35 \pm 51.15$ & $125.9 \pm 54.768$ \\
\hline
\end{tabular}

Table 4: Haemoglobin level at the time of admission and after $24 \mathrm{hrs}$ of delivery.

\begin{tabular}{|c|c|c|}
\hline $\mathrm{Hb}$ & Group 1 & Group 2 \\
\hline At the time of admission & $11.91 \pm 0.91$ & $11.50 \pm 0.88$ \\
\hline 24hrs after delivery & $11.80 \pm 0.78$ & $11.38 \pm 0.75$ \\
\hline Fall in haemoglobin & $0.11 \pm 0.13$ & $0.12 \pm 0.13$ \\
\hline$P$ value & 0.210 & 0.125 \\
\hline
\end{tabular}

\section{DISCUSSION}

The use of oxytocics immediately after the delivery of the baby is one of the most important intervention, to prevent postpartum blood loss, as uterine atony is the most important and common cause of postpartum haemorrhage.

Several studies have reported intraumbilical oxytocin to be effective in reducing the duration of third stage of labour and blood loss. Dahiya et al managed 50 study cases with 10 units of oxytocin diluted in $20 \mathrm{ml}$ saline given through umbilical vein immediately after cord clamping and 50 control, managed actively with 10 units of oxytocin diluted in $250 \mathrm{ml}$ saline at rate of $125 \mathrm{ml} / \mathrm{hr}$ $\mathrm{I} / \mathrm{V}$, given after delivery of the baby. ${ }^{6} \mathrm{He}$ reported significant reduction in duration of third stage of labour $(1.48 \mathrm{~min}$ vs $3.27 \mathrm{~min})$, fall in haemoglobin $(<1.2 \mathrm{~g} / \mathrm{dl}$ vs $1.96 \mathrm{~g} / \mathrm{dl})$ and fall in haematocrit $(<3.88 \%$ vs $7.2 \%)$ in cases as compared to control. Kore et al in 2000, injected 100 patients with 10 units of oxytocin in $20 \mathrm{ml}$ of saline and 100 controls with I.V oxytocin, mean duration of third stage in study group was $5.6 \pm 3.2$ min which was statistically less than $10.2 \pm 2.8 \mathrm{~min}$ in control $(\mathrm{p}<0.01){ }^{7}$ Also, the average blood loss in study group $125 \pm 30 \mathrm{ml}$ was significantly less than control group $275 \pm 55 \mathrm{ml}$ $(\mathrm{p}<0.01)$. Shrestha $\mathrm{P}$ et al, injected 10 units of oxytocin diluted with $10 \mathrm{ml}$ of normal saline given through umbilical vein while control group was managed with 10 units of oxytocin in $500 \mathrm{ml}$ of normal saline through intravenous infusion after delivery of the baby. ${ }^{8}$ She reported the mean blood loss in the third stage of labour was $143.30 \mathrm{ml}$ for the case group and $151.43 \mathrm{ml}$ for the control group while the duration of the third stage of labour was 6.02 and 5.42 minutes for each group respectively. There was significant reduction of blood loss in case group. Ojha et al in 2007, managed 120 women, who were divided into 2 groups administering 10 units of oxytocin; in Group I: oxytocin was diluted mixing with $10 \mathrm{ml}$ of normal saline before it was infused intraumbilical and Group II: injected intramuscularly. ${ }^{9}$ There was no difference in the duration of third stage of labour (3.6 vs. $3.7 \mathrm{~min}$ ) between the two groups. There was no significant blood loss in the intraumbilical group as compared to intramuscular group $(96.2 \pm 79.2 \mathrm{ml}$ vs. $77.7 \pm 58.1 \mathrm{ml}, \mathrm{p}=0.148)$. Manhas A. et al in 2012, conducted a study in which Group 1 received umbilical vein injection of oxytocin. ${ }^{10}$ Group 2 received intraumbilical vein saline injection while subjects in group 3 were managed with systemic methylergometrine, $0.2 \mathrm{mg}$ intravenous at the delivery of anterior shoulder. He reported the reduction of the duration of $3^{\text {rd }}$ stage of labour $(3.17 \pm 1.55$ vs $8.22 \pm 2$ vs $4.6 \pm 2$, $\mathrm{p}=<0.001)$, blood loss in the $3^{\text {rd }}$ stage of labour $(107.11+13.86$ vs $195.04+33.30$ vs $113.17+15.79)$. There was significant difference in the duration of third stage of labour and reduction of blood loss in third stage of labour.

Present study showed significant difference in third stage of labour $1.703 \pm 0.918$ versus $2.931 \pm 0.87, \mathrm{p}=0.00001$ ). There was significant reduction in blood loss in the intraumblical group as compared to intramuscular group $(95.35 \pm 51.15 v s 125.9 \pm 54.768$, p 0.00001). Same results were also observed by Dahiya et al 1995, Shrestha P et al and Manhas A et al. But Ojha et al reported there was no difference in both case and control group.

\section{CONCLUSION}

We concluded that the method of intra-umbilical injection of oxytocin immediately after the delivery of the baby, significantly reduced the duration of the third stage of labour and the amount of blood loss in the third stage of labour as compared to the intramuscular oxytocin. We need large randomarized trial to implement its use in the active management of third stage of labour.

Hence, the results of the review are applicable in underresourced settings where complications of third stage of labor are common and facilities for immediate blood transfusion and surgical intervention are limited.

Funding: No funding sources

Conflict of interest: None declared

Ethical approval: The study was approved by the Institutional Ethics Committee 


\section{REFERENCES}

1. Ministry health and family welfare, Press release;2015.

2. Mukherjee J, Ganguli RP, Saha SR, Maternal Mortality due to haemorrhage with emphasis on PPH. J Obstet Gynecol India. 2001;57(5):130-3.

3. Chamberlain G. The clinical aspects of massive haemorrhage. Maternal Mortality-The Way forward London: RCOG. 1992:54-62.

4. Cunningham G, Leveno KJ, Bloom SL, Hauth JC, Gilstrap LC, Wenstrom KD. William's Obstetrics, 23nd ed. McGraw-Hill Professional, Philadelphia. 2010:310-35.

5. Organization WHO. WHO recommendations for the prevention of postpartum haemorrhage. Geneva: World Health Organization: Department of Making Pregnancy Safer; 2007.

6. Dahiya P, Puri M, Rathee S. Influence of intraumbilical oxytocin on the third stage of labour. Ind J Medic Sci. 1995;49(2):23.
7. Kore S, Srikrishna S, Hedge A, AmbiyeVR VP. Active management of third stage of labour with intraumbilical oxytocin injection. J Obstet Gynecol India. 2000;50(3):54-5.

8. Shrestha P, Babu CS. Influence of umbilical vein oxytocin on blood loss and length of third stage of labour. Nepal Med Coll J; 2007.

9. Ojha N, Malla DS. Active management of third stage of labour by oxytocin: Umbilical vein versus intramuscular use. N J Obstet Gynecol. 20074;2(1):13-6.

10. Manhas A, Habib H. A randomized controlled study of prophylactic use of umbilical vein oxytocin in the management of third stage of labor. IOSR-JDMS. 2012;1(6):27-30.

Cite this article as: Gupta N, Athokpam M. Active management of third stage of labour: a comparative study of intra-umbilical oxytocin versus intramuscular oxytocin. Int J Reprod Contracept Obstet Gynecol 2017;6:3434-7. 